\title{
PENGEMBANGAN MODEL RESIPROCAL, EXAMPLE NON EXAMPLE, DAN MIND MAPPING (REXMIND) UNTUK MENGOPTIMALISASI HASIL PEMBELAJARAN ILMU PENGETAHUAN SOSIAL (IPS) DI KELAS VII
}

\author{
Sri Sariningsih", Adi E. Yusuf ${ }^{2}$, Entis Sutisna², Griet Helena Laihad ${ }^{2}$ \\ ${ }^{1}$ Guru SMPN 1 Nyalindung Sukabumi, Jawa Barat \\ ${ }^{2}$ Program Pascasarjana Universitas Pakuan \\ Email: pasca@unpak.ac.id
}

\begin{abstract}
The research aims to optimize Sosial Study learning outcomes of class VII through a model development research $(R \& D)$. The model that will be developed is REXMIND model which is combining Reciprocal learning, Example Non-Example, and Mind Mapping. A limited trial was conducted at SMPN 1 Cireunghas with 36 students, as well as an extensive trials conducted at SMPN 1 Nyalindung with 36 students, and at SMPN 3 Nyalindung with 23 students. The methods that used are survey method of qualitative and quantitative data collection techniques. The assessment of student learning outcomes on a limited trial at SMPN 1 Cireunghas in the cognitive domain was $91.67 \%$, in the affective sphere was $87 \%$, in the psychomotor realm $88 \%$, and in the students enthusiasm $88.7 \%$, with the minimal mastery criteria "KKM" 70. The assessment of student learning outcomes in the limited trials at SMPN 1 Nyalindung in the cognitive domain was $94.44 \%$, in the affective sphere was $89 \%$, in the psychomotor domain $91 \%$, and in the students enthusiasm 92\%, with the minimal mastery criteria "KKM" 70. The assessment of student learning outcomes in the limited trial at SMPN 3 Nyalindung in the cognitive domain was $91.3 \%$, in the affective domain was $85 \%$, in the psychomotor domain $86 \%$, and in the students enthusiasm $92 \%$, with minimal mastery criteria "KKM" 70. This research recommended that the model development, REXMIND Model, on Sosial Study in Region Sukaraja (Reciprocal learning, Example Non-Example, and Mind Mapping) was able to improve the learning outcomes both cognitively and affectively, as well as psychomotor skills and student's enthusiasm. This research recommended a developed learning model, namely; REXMIND model (Reciprocal learning, Example Non-Example, and Mind Mapping)
\end{abstract}

Key words: Reciprocal Learning, Example Non-Example, and Mind Mapping

\begin{abstract}
ABSTRAK
Tujuan penelitian ini untuk mengoptimalisasi hasil pembelajaran ilmu pengetahuan sosial (ips) di kelas VII melalui pengembangan model resiprocal, example non example, dan mindmapping (rexmind). Penelitian ini digolongkan ke dalam penelitian Research and Development (R\&D) dengan menggabungkan Model pembelajaran Reciprocal, Example Non-Example, dan Mind Mapping. Uji coba terbatas dilaksanakan di SMPN 1 Cireunghas dengan 36 SISWA, dan uji coba luas di SMPN 1 Nyalindung dengan 36 siswa dan SMPN 3 Nyalindung dengan 23 siswa. Metode yang digunakan adalah metode survey dan teknik pengumpulan data kualitatif dan kuantitatif. Penilaian hasil belajar siswa pada uji coba terbatas pada ranah kognitif adalah $91.67 \%$, afektif adalah $87 \%$, psikomotor $88 \%$ dan antusiasme siswa 88.7\% dengan KKM 70. Penilaian hasil belajar siswa pada uji coba luas pada ranah kognitif adalah $94.44 \%$, afektif adalah $89 \%$, psikomotor $91 \%$ dan antusiasme siswa 92\% dengan KKM 70. Penilaian hasil
\end{abstract}


belajar siswa pada uji coba luas pada ranah kognitif adalah $91.3 \%$, afektif $85 \%$, psikomotor $86 \%$ dan antusiasme siswa $92.50 \%$ dengan KKM 70. Penelitian ini merekomendasikan bahwa Pengembangan Model REXMIND pada Mata Pelajaran IPS Se-Komisariat Sukaraja (Reciprocal, Example Non-Example, dan Mind Mapping) berhasil meningkatkan hasil belajar baik secara kognitif, afektif, psikomotorik dan antusiasme siswa . Penelitian Research and Development (R \& D) ini menghasilkan model pembelajaran baru yang terekomendasi yaitu Model REXMIND (Reciprocal, Example Non-Example, dan Mind Mapping).

Kata Kunci : Reciprocal Learning, Example Non-Example, dan Mind Mapping

\section{PENDAHULUAN}

Pendidikan merupakan usaha untuk mempersiapkan manusia agar menjadi lebih baik dalam kualitas hidupnya. Di era globalisasi ini tantangan hidup semakin kompleks. Peran pendidikan semakin berat. Sistem pendidikan yang terselenggara harus mampu menghadapi tantangan untuk menyediakan sumber daya manusia yang berkualitas sehingga mampu menghadapi tantangan zaman. Peran pendidikan yang cukup berat tersebut berimplikasi terhadap tuntutan pendidikan yang semakin diharapkan bermutu serta membentuk karakteristik bangsa yang intelek, maju dalam segala bidang, membentuk perilaku yang baik sehingga dapat menjadi bekal dalam menghadapi era globalisasi yang semakin kompetitif dan sebagai antisipasi kepentingan masa depan.

Ilmu Pengetahuan Sosial IPS berupaya membangkitkan minat manusia agar mau meningkatkan kecerdasan dan pemahamannya tentang alam dan semua isinya yang penuh dengan rahasia yang tak habis-habisnya. Persepsi pelajaran IPS terutama Sejarah adalah materi pelajaran yang sangat sulit dan membosankan, sehingga perlu alternatif pembalajaran lain untuk membangkitkan minat siswa diantaranya dengan menggunakan model pembelajaran yang inovatif, variatif dan menyenangkan.

\section{Model Pembelajaran Bahasa Inggris \\ a. Model Pembelajaran}

Menurut Sagala dalam Sudaryono (2010: 60-61) pembelajaran adalah setiap kegiatan yang dirancang untuk membantu seseorang mempelajari suatu kemampuan dan atau nilai yang baru. Rancangan yang dimaksud adalah kesiapan guru untuk mengenal karakteristik siswa sehingga tercapai indikator pembelajaran baik dalam ranah kognitif, afektif, dan psikomotor siswa. Sedangkan, menurut Trianto (2010:17) pembelajaran hakikatnya adalah usaha sadar dari seorang guru untuk membelajarkan siswanya (mengarahkan interaksi siswa dengan sumber belajar lainnya) dalam rangka mencapai tujuan yang diharapkan Sejalan dengan pendapat di atas disebutkan juga bahwa pembelajaran adalah kegiatan mengimplementasikan kurikulum satuan pendidikan agar tercapai tujuan pembelajaran yang telah di tetapkan Ahmad. (2013:24).Dari pendapat para ahli dapat disintesiskan pembelajaran adalah merupakan proses mengupayakan atau memfasilitasi peserta didik mencapai tujuan pembelajaran/kompetensi yang telah ditetapkan sehingga memperoleh pengalaman belajar sesuai tujuan kurikulum.

\section{b. Pelajaran IPS}

Mulyono. (1980: 8) memberi batasan IPS sebagai pendekatan interdisipliner (Interdisciplinary approach) dari pelajaran Ilmu-ilmu sosial. IPS merupakan integrasi dari berbagai cabang ilmu-ilmu sosial, seperti sosiologi, antropologi budaya, psikologi sosial, sejarah, geografi, ekonomi, ilmu politik, dan sebagainya. Hal ini lebih ditegaskan lagi oleh Saidiharjo (1996: 4), bahwa IPS merupakan hasil kombinasi atau basil pemfusian atau perpaduan dari sejumlah mata pelajaran seperti geografi, ekonomi, sejarah, antropologi, dan politik. Aspek 
kehidupan social terkait dengan ruang tempat tinggalnya apapun yang dipelajari, apakah itu hubungan social, ekonomi, budaya, kejiwaan, sejarah, geografis, atau politik, sumbernya adalah masyarakat Winataputra dalam Iwan (2016: 8).

Berdasarkan pendapat para ahli diatas dapat disintesiskan bahwa pelajaran IPS di tingkat Sekolah Menengah Pertama merupakan satu pelajaran terpadu yang mengintegrasika empat mata pelajaran, yaitu; geografi, ekonomi, sosiolgi, dan sejarah.

\section{Hasil Belajar}

Bloom dalam Suprijono (2010:6) mengatakan hasil belajar yaitu mencakup kemampuan kognitif, afektif dan psikomotor. Menurut Dimyati (2006: 3-5) hasil belajar merupakan hasil dari suatu interaksi tindak belajar dan tindak mengajar . Dari sisi guru, tindak mengajar diakhiri dengan proses evaluasi hasil belajar ,untuk bisa mengetahui keberhasilan tujuan pembelajaran.

Berdasarkan beberapa teori di atas dapat disintesiskan bahwa hasil belajar IPS adalah hasil akhir dari sebuah proses pembelajaran yang mencakup adanya peningkatan perubahan baik dilihat dari pengetahuan, keterampilan, maupun sikap sesuai dengan tujuan pembelajaran yang telah ditetapkan berdasarkan kurikulum yang berlaku, dari hasil belajar tersebut dapat menunjukan berhasil atau tidaknya sebuah tujuan pembelajaran, atau target pembelajaran, sehingga akan ada peningkatan pada perubahan pengetahuan, keterampilan dan perubahan tingkahlaku/sikap.

\section{Model Pembelajaran}

Arends dalam Trianto menyatakan, "The term teaching model refers to a particular approach to instruction that includes its goals, syntax, environment, and managements system." Istilah model pembelajaran mengarah pada suatu pendekatan pembelajaran tertentu termasuk tujuan, sintaks, lingkungan, dan sistem pengelolaan. Trianto (2009: 22). Agus Suprijono (2016: 65) menyatakan Model pembelajaran adalah pola yang digunakan sebagai pedoman dalam merencanakan pembelajaran di kelas maupun tutorial. Dan berfungsi sebagai pedoman bagi bagi para pengajar dalam merencanakan aktivitas belajar mengajar.

Dengan demikian dapat disintesiskan bahwa model pembelajaran adalah pendekatan, strategi, metode, teknik dan taktik pembelajaran yang merupakan bentuk pembelajaran yang tergambar dari awal sampai akhir yang disajikan secara khas oleh guru dalam menyampaikan pesan atau materi pelajaran, meliputi aspek kognitif, apektif, dan psikomotor

\section{Resiprocal}

Model pembelajaran reciprocal merupakan pengajaran yang melakukan pendekatan terbalik sebagai strateginya. Menurut Nur dan Wikandari dalam Trianto (2010: 173) pengajaran terbalik adalah pembelajaran yang menggunakan pendekatan konstruktivis yang berdasar pada prinsip-prinsip pembuatan/ pengajuan pertanyaan, dimana keterampilanketerampilan mega kognitif diajarkan melalui pengajaran langsung dan pemodelan oleh guru untuk memperbaiki kinerja membeca siswa yang membaca pemahamannya rendah. Menurut Suratmo (2008: 152) pengertian Strategi Resiprocal Teaching merupakan suatu prosedur pembelajaran kooperatif yang mengacu kepada siswa untuk bekerja sama dalam kelompok kecil dan saling membantu dalam proses belajar. Dalam strategi ini terdapat empat strtegi dasar, yaitu menyusun pertanyaan, memprediksi jawaban, mengklarifikasi jawaban, dan membuat rangkuman.

Dari pendapat para ahli dapat disintesiskan bahwa teknik pembelajaran reciprocal merupakan teknik pembelajaran terbalik, dimana siswa diberikan materi terlebih dahulu oleh guru untuk dipelajari dan dirangkum. Rangkuman tersebut berupa poin-poin yang penting. Poin-poin tersebut nantinya akan dipresentasikan dan diterangkan di depan siswa yang lainnya 


\section{Model Example Non-Example}

Example Non-Example merupakan strtegi pembelajaran yang menggunakan gambar sebagai media untuk menyampaikan materi pembelajaran. Menurut Kurniadi (2010: 1) menyatakan bahwa "model pembelajaran Example Non-Example merupakan model pembelajaran yang menggunakan gambar sebagai media pembelajaran. Menurut Imas Kurniasih dan Sani (2015: 32) model pembelajaran Example Non-Example merupakan sebuah langkah untuk mensiasati agar siswa dapat mendefinisikan sebuah konsep. Adapun strategi yang digunakan bertujuan untuk mempersiapkan siswa secara cepat dengan menggunakan dua hal yang teridri dari example (contoh suatu materi yang akan dibahas) dan Non-Example (contoh materi yang tidak dibahas), dan meminta siswa untuk mengklasifikasi keduanya sesuai konsep yang ada.

Dari uraian di atas dapat disimpulkan bahwa model pembelajaran Examples NonExamples merupakan model pembelajaran yang menggunakan contoh gambar-gambar dalam pembelajarannya.

\section{Model Pembelajaran Mind Mapping}

Menurut Sugianto dalam Mulyatiningsih (2014: 238) pemetaan pikiran (Mind Mapping) adalah teknis meringkas bahan yang perlu dipelajari, dan memproyeksikan masalah yang dihadapi ke dalam bentuk peta atau teknik grafik sehingga mudah memahaminya.. Kuniasih dan Berlin Sani (2016: 53) menyatakan bahwa Mind Mapping merupakan cara untuk menempatkan informasi ke dalam otak dan mengambilnya kembali ke luar otak.

Berdasarkan uraian di atas dapat disimpulkan bahwa Mind Mapping adalah suatu cara kreatif dalam membuat sebuah ringkasan dalam bentuk kata, simbol, gambar dengan warna warna yang menarik yang dituangkan pada selembar kertas polos dengan tujuan untuk memudahkan pemanggilan kembali informasi yang sudah didapat.

\section{Model Pembelajaran REXMIND}

REXMIND adalah model pembelajaran yang lahir dari penggabungan model, teknik dan media pembelajaran yang dianggap mampu dan dapat digunakan untuk mengatasi permasalahan yang ditemukan dalam proses pembelajaran.

\section{METODE PENELITIAN}

Metode penelitian yang digunakan adalah metode Research and Development ( $R \& D)$. Kegiatan penelitian ini dilaksanakan di wilayah komsariat Sukaraja, sehingga pelaksanaannya pun dilakukan dengan kerjasama peneliti dengan guru-guru IPS anggota MGMP IPS komisariat Sukaraja sekaligus sebagai partner dalam penelitian ini. Kegiatan penelitian ini dilaksanakan di wilayah komsariat Sukaraja, sehingga pelaksanaannya pun dilakukan dengan kerjasama peneliti dengan guru-guru IPS anggota MGMP IPS komisariat Sukaraja sekaligus sebagai partner dalam penelitian ini.

Langkah-langkah penggunaan metode Research and Development $(R \& D)$

1. Langkah pertama pendahuluan yang meliputi:

a. Studi Pendahuluan (Research and Information Collecting).

Pada tahap ini meliputi analisis kebutuhan, studi pustaka. Studi literature, penelitian skala kecil dan standar laporan sesuai yang dibutuhkan.

b. Merencanakan Penelitian (Planning)

Perencanaan penelitian R\&D meliputi; merumuskan tujuan penelitian, memperkirakan dana, tenaga, waktu; merumuskann kualifikasi peneliti dan bentukbentuk partisivasinya dalam penelitiannya. 
2. Langkah kedua Pengembangan yang meliputi: Pengembangan Desain (Develop preliminary of Product). Langkah ini meliputi: menentukan desain produk yang akan dikembangkan, menentukan sarana dan prasarana penelitian yang dibutuhkan selama proses penelitian dan pengembangan, menentukan tahap-tahap pelaksanaan uji desain di lapangan, dan menentukan deskripsi tugas pihak-pihak yang terlibat dalam penelitian.

3. Langkah ketiga uji lapangan yang meliputi:

a. Uji coba terbatas (Preliminary Field Testing). Pada tahap ini adalah tahap dimana pelaksanaan uji produk secara terbatas.

b. Revisi hasil uji coba(Main Product Revision)Setelah dilaksanakan uji produk secara terbatas berikutnya yaitu tahap perbaikan model atau desain berdasarkan uji lapangan yang telah dilakukan secara terbatas.

c. Uji coba Luas(Main Field testing). Langkah selanjutnya adalah menguji kembali produk atau model yang sudah diperbaiki atau mengalami penyempurnaan dari produk awal

d. Revisi hasil Uji coba luas(Operational Product Revision). Setelah diuji coba secara luas, kembali model atau produk direvisi agar lebih sempurna dengan berpatokan pada pelaksaaan uji secara luas.

e. Uji kelayakan (Operational Field Testing). Untuk mengetahui apakah model atau produk dpat dikatan layak maka harus dilakukan uji kelayan, uji kelayakan ini dilakukan oleh tim ahli yang sudah dipersiapkan.

f. Revisi Hasil uji kelayakan(Final Product Revision. Setelah dilakukan uji kelayakan oleh tim ahli dan ternyata masih ada kekurangan maka produk akan direvisi kembali sehingga mencapai kesempurnaan.

4. Langkah keempat disseminasi

Desiminasi atau Implementasi Produk Akhir (Dissemination and Implementation). Pada tahap ini adalah tahap terakhir dari serangkaian langkah yang terdapat dalam penelitian dan pengembangan yaitu tahap diseminasi atau implementasi produk.

Penelitian ini dilakukan di 3 SMP Negeri yang ada di komisariat Sukaraja, kabupaten Sukabumi provinsi Jawa Barat. Waktu pelaksanaan selama satu semester genap tahun pelajarana 2017-2018. Pada pelaksanaannya uji coba model pembelajaran akan dilaksanakan oleh tiga orang guru model dari MGMP IPS yang diminta untuk menjadi tempat pelaksanaan uji coba model secara terbatas dan uji coba secara luas.

Uji coba terbatas dilaksanakan di SMPN 1 Cireunghas kabupaten Sukabumi sebagai sekolah midle, dengan bantuan guru model rekan kerja dari sekolah yang sama. Uji coba luas pertama dilaksanakan di SMPN 3 Nyalindung kabupaten Sukabumi, adalah sebuah sekolah negeri yang jaraknya relatif dekat dengan sekolah pelaksanaan uji terbatas. Dan uji coba dibantu oleh seorang guru model dari sekolah tersebut. Uji coba luas berikutnya dilaksanakan Di SMPN 1 Nyalindung, yaitu sekolah dimana penulis melaksanakan tugas.

Sedangkan pengembangan draft model meliputi; perencanaan, pengorganisasian, pelaksanaan, dan evaluasi.

1. Tahap Perencanaan

Pada tahap ini yang akan dilakukan adalah :

a. Identifikasi masalah

b. Menyusun pengembangan model

c. Menyusun jadwal penelitian

d. Menentukan tempat sasaran dan menentukan guru model dalam pelaksanaan uji coba model pembelajaran

e. Menyiapkan perangkat pembelajaran, diantaranya ; silabus, RPP, LKS, dan Media pembelajarn 
f. Menentukan tim kolaborasi

g. Menyiapkan alat bantu observasi untuk guru, siswa dan peneliti

h. Membuat rencana setting kelas disekolah sasaran

i. Menyusun instrumen tes dan non tes untuk mengukur keberhasilan siswa yang meliputi aspek sikap, kognitif, dan psikomotor.

2. Tahap pengorganisasian

Pada tahap ini yang akan dilakukan adalah menentukan expert judgement yang akan memvalidasi model pembelajaran yang diciptakan dari berbagai aspek, baik itu yang berhubungan dengan dengan konten yaitu kesesuaian materi, serta langkah-langkah dari model pembelajaran. Untuk expert judgement akan ilakukan oleh dosen IPS yang ada di Universitas Pakuan Bogor, sedangkan untuk langkah-langkah model pembelajarannya dilakukan oleh pengawas mata pelajaran IPS di dinas pendidikan kabupaten Sukabumi.

3. Tahap Pelaksanaan

Pelaksanaan adalah merupakan realisasi dari sebuah perencanaan, dan dalam pembelajaran pelaksanaan adalah tindakan yang dilakukan oleh guru dengan menggunakan acuan berupa RPP.

4. Tahap Evaluasi

Pada tahap ini evaluasi dilaksanakan selama proses pembelajaran berlangsung, dengan berpatokan pada instrument yang telah disediakan. Bertujuan untuk mengetahui apakah pelaksanaan dalam menerapkan model pembelajaran REXMIND sesuai dengan Rencana Pelaksanaan Pembelajaran yang telah disusun. Dan hasilnya akan dijadian acuan dalam memperbaiki / merevsisi model pada setiap pertemuan.

Evaluasi pembelajaran adalah suatu proses atau kegiatan yang sistematis, berkelanjutan, dan menyeluruh dalam rangka pengendalian, penjaminan, dan penetapan kualitas (nilai dan arti ) pembelajaran terhadap berbagai komponen pembelajaran, berdasarkan pertimbangan dan kriteria tertentu, sebagai bentuk pertanggung jawaban guru dalam melaksanakan pembelajaran. Sistem Evaluasi adalah suatu sistem penilaian yang dilakukan untuk mengetahui pengetahuan dan kecakapan siswa dalam menerima, memahami dan menalar bahan ajar yang diberikan sesuai dengan kurikulum dan silabus yang telah ditetapkan serta untuk mengetahui perubahan sikap dan keterampilan siswa.

Evaluasi dilaksanakan terhadap semua aktivitas guru dan siswa dalam proses pembelajaran sesuai dengan kriteria keberhasilan yang ingin dicapai dan materi yang disampaikan. Pada penelitian ini evaluasi akan dilaksanakan meliputi Tes dan Non Tes.

\section{HASIL PENELITIAN}

Dari hasil evaluasi kognitif yang diperoleh oleh siswa pada uji coba terbatas yang dilaksanakan di SMPN 1 Cireunghas setelah proses penerapan model pembelajaran REXMIND menunjukan adanya peningkatan dari hasil pra uji coba model yaitu dengan ketuntasan klasikal $50 \%$, meningkat setelah dikenakan tindakan yaitu 91,67\%.

Dari hasil evaluasi afektif yang diperoleh oleh siswa pada uji coba terbatas yang dilaksanakan di SMPN 1 Cireunghas setelah proses penerapan model pembelajaran REXMIND menunjukan adanya peningkatan dari hasil pra uji coba model yaitu dengan nilai $77 \%$ dan pasca uji coba model $87 \%$.

Hasil belajar psikomotorik diperoleh dalam bentuk keterampilan dan kemampuan individu saat dan setelah mendapat pengalaman belajar. Pengamatan psikomotorik siswa diamati pada setiap tindakan yang dilakukan pada setiap uji coba berlangsung.

Hasil Antusiasme Siswa adalah salah satu yang menjadi poin pengamatan dalam pelaksanakan penelitian dan pengembangan (Research and Development). Pengamatan 
antusiasme siswa diamati pada setiap tindakan yang dilakukan pada setiap uji coba berlangsung. Hasil antusiasme siswa pada pada saat pertemuan pertama pada uji coba terbatas di SMPN 1 Cireunghas rata-rata aktivitas on tasknya adalah $73.30 \%$ dan Off tasknya adalah $26.70 \%$ terjadi perubahan kearah yang lebih baik, pada pertemuan kedua On tasknya adalah $88,75 \%$ dan off tasknya adalah $11.25 \%$. Hasil antusiasme siswa pada pada saat pertemuan pertama pada uji coba luas di SMPN 1 Nyalindung rata-rata aktivitas on tasknya adalah 76.25 $\%$ dan Off tasknya adalah $23.75 \%$ terjadi perubahan kearah yang lebih baik, pada pertemuan kedua On tasknya adalah $92.50 \%$ dan off tasknya adalah $7.50 \%$. Hasil antusiasme siswa pada pada saat pertemuan pertama pada uji coba luas di MTS Darul Fikri rata-rata aktivitas on tasknya adalah $60 \%$ dan Off tasknya adalah $40 \%$ terjadi perubahan kearah yang lebih baik, pada pertemuan kedua On tasknya adalah $92.50 \%$ dan off tasknya adalah $7.50 \%$.

\section{PEMBAHASAN}

Berdasarkan hasil penelitian Delphi 1, 2, dan 3 penggunaan model pemeblajaran REXMIND menunjukkan adanya keberhasilan yang memuaskan. Hal ini terlihat pada terhadap peningkatan terhadap hasil belajar yang meliputi tiga ranah (kognitif, afektif, dan psikomotor) dan antusiasme. Penilaian autentik yang diterapkan (authentic assessment) merupakan karakteristik yang menandai pemberlakuan kurikulum 2013. Penilaian autentik sebagai penilaian yang nyata menggambarkan prestasi belajar siswa sesuai dengan kemampuan mereka yang sesungguhnya melalui aspek kognitif, afektif dan psikomotorik.

Perbandingan hasil belajar baik pada ranah kognitif, afektif dan psikomotorik di masingmasing sekolah mengalami peningkatan setelah diterapkannya model REXMIND. Konsep penerapan model ini meningkatkan pengetahuan siswa melalui reciprocal dengan pengulangan pertanyaan yang disampaikan oleh guru model. Dipadukan dengan Example Non-Example untuk lebih mengkonsentrasikan siswa pada dengan menampilkan gambar-gambar, dan untuk lebih menguatkan lagi ingatan mengenai materi pembelajran maka hasil dari rangkumannya diterapkan dalam pembuatan mind mapping dengan komposisi anggota yang heterogen disetiap kelompok, sehingga siswa lebih termotivasi untuk menuangkannya. Kerjasama antar anggota kelompok sangat diutamakan.

Berikut penilaian hasil belajar siswa pada uji coba terbatas di SMPN 1 Cireunghas pada ranah kognitif adalah $91.67 \%$, ranah afektif adalah $87 \%$, ranah psikomotor $88 \%$ dan antusiasme siswa $88.7 \%$ dengan KKM 70. Penilaian hasil belajar siswa pada uji coba luas di SMPN 1 Nyalindung pada ranah kognitif adalah $94.44 \%$, ranah afektif adalah $89 \%$, ranah psikomotor $91 \%$ dan antusiasme siswa 92\% dengan KKM 70. Penilaian hasil belajar siswa pada uji coba luas di SMPN 3 Nyalindung pada ranah kognitif adalah $91.3 \%$, ranah afektif adalah $85 \%$, ranah psikomotor $86 \%$ dan antusiasme siswa $92.50 \%$ dengan KKM 70.

\section{SIMPULAN}

Berdasarkan proses pengembangan model yang sudah dilaksanakan dan validasi model oleh Expert Judgement melalui penelitian dan pengembangan (Research and Development) maka diperoleh hasil yaitu sebuah model terekomendasi dengan nama Model Pembelajaran REXMIND (Reciprocal, Example Non-Example, dan Mind Mapping).

Model pembelajaran REXMIND adalah model pembelajaran yang dirancang untuk menjawab permasalahan pembelajaran yang banyak ditemukan dalam proses pembelajaran. 
Model ini lahir dari kolaborasi tiga buah model pembelajaran yang sudah ada dan satu buah media pembelajaran (Reciprocal, Example Non-Example, dan Mind Mapping).

Model pembelajaran REXMIND ini berarah pada proses pembelajran yang mengimplementasikan pendekatan saintifik yang meyentuh tiga ranah, yaitu pengetahuan (kognitif), sikap (afektif) dan keterampilan (psikomotorik).

\section{DAFTAR PUSTAKA}

Agus Suprijono, 2016. Cooperative Learning teori dan aplikasinya. Pustaka Pelajar Yogyakarta.

Ahmad Tafsir. 2013. Ilmu Pendidikan Dalam Perspektif Islam. Bandung: PT. Rosda.

Dimyati dan Mudjiono. 2010. Belajar dan Pembelajaran. Jakarta : Rieneka Cipta.

Endang Mulyatiningsih. 2014. Metode Penelitian Terapan Bidang Pendidikan. Bandung: Alfabeta.

Imas Kurniasih dan Berlin Sani. 2015. Ragam Pengembangan dan Model Pembelajaran. Jogyakarta: Kata Pena.

Iwan setiawan. 2016. Buku Guru Ilmu Pengetahuan Sosial SMP Kelas VII Kurikulum 2013

Edisi Revisi. Jakarta: Kementrian Pendidikan dan Kebudayaan.

Mulyono Tj. 1980. Media dan Lab IPS. Jakarta: Depdikbud

Sudaryono. 2012. Dasar-dasar Evaluasi Pembelajaran. Yogyakarta: Graha Ilmu.

Suratmo. 2018. Macam-Macam Sumber Belajar. Jakarta: Gramedia.

Trianto. 2007. Model-Model Pembelajaran Inovatif berorientasi konstruktif. Jakarta : Prestasi Pustaka Publisher.

Trianto. 2010. Mendesain Model pembelajaran Inovatif-Progressif. Jakarta: Kencana. 